\title{
COMPARISON OF DIMENSIONAL STABILITY AND SURFACE DETAIL REPRODUCTION OF SILICONE BASED IMPRESSION MATERIALS.
}

\author{
Riwaj Karki and Dipendra Naulakha
}

\begin{abstract}
Background: Performance of newly introduced modified silicone based impression materials regarding dimensional stability and the capability of surface detail reproduction remains to be known.

Objective: To compare the dimensional stability and surface detail reproduction of addition silicone and condensation silicone impression materials.

Materials and methods: This is an in-vitro study, total 80 impressions were taken (40 impressions of addition silicone and 40 impressions of condensation silicone impression material) of a standard stainless steel die. Dimensional stability was evaluated at 30 minutes, 24 hours and 48 hours of impression making by the use of a travelling microscope and surface detail reproduction was evaluated at 10 minutes of impression making by the use of stereomicroscope. Data were processed and analyzed using SPSS. Significance test was done using unpaired ' $t$ ' test and Chi square $\left(\boldsymbol{X}^{2}\right)$ test.
\end{abstract}

Results: Addition silicone and condensation silicone impression materials had no significant difference $(\mathrm{p}>0.05)$ in surface detail reproductions at 10 minutes and dimensional stability at 30 minutes of impression making but at 24 hours and 48 hours of impression making dimensionally stability was significantly higher $(\mathrm{p}<0.05)$ in addition silicone than that of condensation silicone impression materials.

Conclusion: Addition silicone impression materials have better dimensional stability than condensation silicone impression materials in terms of storage and similar surface detail reproduction capacity at 10 minutes of impression making.

Keywords: Diamensional stability, silicone impression materials, Surface detail reproduction

\section{Introduction}

Accurate reproduction of the prepared tooth and other oro-dental structure is of critical importance in the fabrication of a fixed or removable restorations or prostheses. Inaccuracies in the replication process will ultimately have an adverse effect on the fit and adaptation of the final restoration.
Some silicone impression materials undergo changes with time; for example, a material may be highly dimensionally accurate soon after its initial polymerization but less accurate after storage for a period due to evaporation of its by product. Dentists may have to wait for considerable time for pouring impressions; therefore, it is important that an 
impression material should be dimensionally stable ${ }^{1,2,3}$.

Silicone impression materials are supplied in different viscosities: very high viscosity/putty, heavy viscosity, medium viscosity and low viscosity. The optimum mixture for accurate impression making is to use as little low viscosity material as possible to capture the fine details of the prepared margin, while the mass of the impression material should be made with very high viscosity/putty. Dimension stability of wash impression mainly depends on very high viscosity/putty ${ }^{4}$. Putty material was developed to overcome the polymerization shrinkage of the condensation silicone impression materials. Besides acting as a tray material this putty is also used for border moulding of complete denture and obturators $^{3}$.

Silicone impression materials are hydrophobic to make hydrophilic internal surfactant as "nonylphenoxy polyethanol" added to addition silicone 5 . For ease and comfort of the patient; putty material are also available as fast setting and as soft putty to increase the flexibility for easy removal from the undercuts ${ }^{6,7}$. These newer formulations silicone impression materials dimensional stability and the capability of surface detail reproduction remains to be known. Therefore the purpose of the study was to compare the dimensional stability and surface detail reproduction of addition silicone and condensation silicone impression materials.

\section{Materials and methods}

In this study, addition silicone and condensation silicone putty impression material of were assessed for dimensional stability and surface detail reproduction. Total 80 impressions were obtained from standard stainless steel die (40 impressions in group A and 40 impressions in group B) were taken as sample of the study and the materials used are shown in Table I. Sample selection was done on the basis of inclusion criteria which are freshly prepared impression; the impression without any surface roughness during removal from the test block and exclusion criteria was deformed impression; impression containing pits, voids and marginal defects.

A round stainless steel die was used for testing the dimensional stability and surface detail reproduction of the impression ${ }^{8}$ shown in Fig: 1.

Impressions of addition silicone putty and condensation silicone putty impression material were dispensed and mixed according to manufacturers' recommendations.

The mixed material was placed on the marked surface of the die after placing the round metal ring. The stainless steel tray was then placed over the impression. A gradual constantly increasing pressure was applied to the tray in order to expel the excess material till it completely seats on the ring and a weight of $1 \mathrm{~kg}$ was placed over the tray. This whole assembly was immediately transferred to a water bath at $32 \pm 2$ a 8 $^{8,9}$. The impressions were allowed to set for 3 minutes longer than the recommended time of setting to assure the complete polymerization. Afterward impression was separated along with the ring and perforated tray. Impressions with inclusion criteria were selected as a sample of the study. These selected impressions were numbered and stored in a normal room temperature and humidity.

The XX' distance of middle horizontal line at different interval of time (30 minutes, 24 hours and 48 hours) was measured on the selected impressions. This measurement was done 3 times to the nearest $0.01 \mathrm{~mm}$ at original magnification $\times 10$ using a travelling microscope and average value of 3 measured length was taken. This average length was compared with the measurement of the same line on the standard stainless steel die used to make the impressions and on the basis of discrepancies of measurement dimensional stability was evaluated ${ }^{9}$. 
The percent dimensional change of the impression was evaluated by using the following equation:

\section{${ }^{*}$ M.I.M $-{ }^{*}$ S.D.M $\quad$ X 100}

S.D.M

"M.I.M: Mean impression measurement, ${ }^{*}$ S.D.M: standard die measurement.

Surface detail reproduction was evaluated by giving the grading to the continuity of the horizontal line replicated on the selected impression $^{10}$ at 10 minutes by using stereomicroscope at the $\times 30$ magnification. Grading of reproduced horizontal line on impression surface: Grade1: Full length reproduction without break in the continuity of line.Grade2: Full length reproduction with break in the continuity of line. Grade 3: Not detectable or failure to reproduce the line. Data were taken and collected in a data collection sheet. Statistical analysis for comparison between groups; for quantitative variables unpaired ' $t$ ' test and for qualitative variables Chi square $\left(\boldsymbol{X}^{2}\right)$ test was performed. The level of significance was set at 0.05 and $\mathrm{p}<0.05$ considered significant. The summarized data were interpreted accordingly and were then presented in the form of tables and graphs.

\section{Results}

The results were expressed in the tables and line diagrams. The addition silicone and condensation silicone impression materials had similar dimensional stability at 30 minutes (Table II) of impression making but when the impressions were stored for 24 hours (Table III) and the following 48 hours (Table IV) addition silicone impression materials was significantly more dimensionally stable than that of condensation silicone impression materials as in Figure 4 and 5 shows. Where as, in terms of surface detail reproductions the reproducibility of both impression materials had no significant differences at 10 minutes of impression making as in Table III.

\section{Discussion}

Success of any prostheses depends primarily on the accuracy of impression and if any inaccuracies in the surface detail reproduction will ultimately have an adverse effect on the fit and adaptation of the final restoration.

\begin{tabular}{|c|c|c|c|c|}
\hline Material & $\begin{array}{c}\text { Lot } \\
\text { n.o. }\end{array}$ & $\begin{array}{c}\text { Expiry } \\
\text { Date }\end{array}$ & $\begin{array}{c}\text { Manufactu } \\
\text { rer }\end{array}$ & Made In \\
\hline $\begin{array}{c}\text { Aquasil } \\
\text { (Addition } \\
\text { silicone putty } \\
\text { impression } \\
\text { material) }\end{array}$ & 09110 & $2013-11$ & Dentsply & Germany \\
\hline $\begin{array}{c}\text { Zetaplus } \\
\text { (Condensation } \\
\text { silicone putty } \\
\text { impression } \\
\text { material) }\end{array}$ & 71279 & $2014-05$ & $\begin{array}{c}\text { Zhermack } \\
\text { Clinical }\end{array}$ & Italy \\
\hline
\end{tabular}

Table I: Impression materials used.

Fig 1: Stainless steel die,
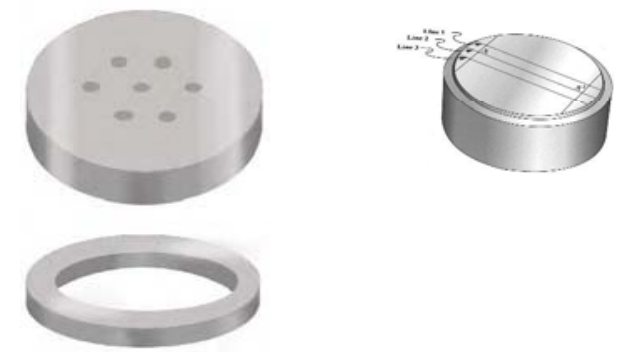

Perforated trey and ring.

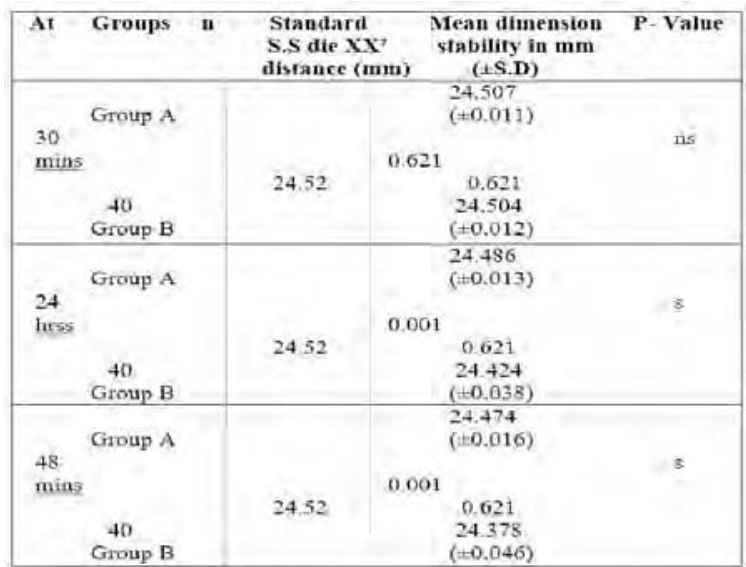




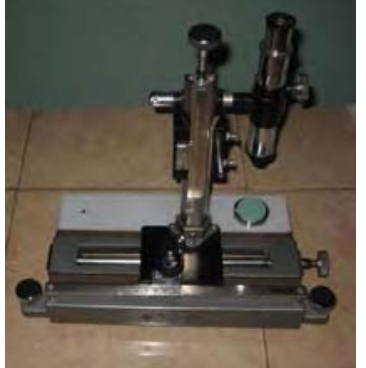

Fig2:Travelling Microscope measuring $\mathrm{XX}^{\prime}$ distance.

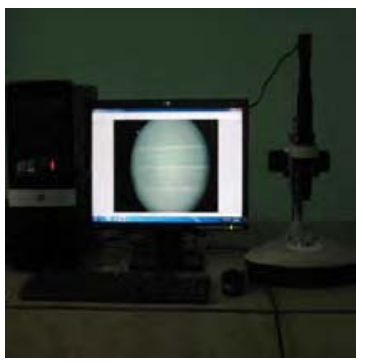

Fig3: Surface Detail

*P- value obtained from unpaired sample t-test reproduction checking with

*Group-A: Impression with addition silicone impression material. Stereomicroscope.

*Group-A: Impression with addition silicone impression material.

*Group-B: Impression with condensation silicone impression material.

*XX': Length of middle horizontal line in between the vertical line.

${ }^{*} \mathrm{~ns}=$ Not significant, ${ }_{\mathrm{s}} \mathrm{s}=$ Significant, ${ }^{*} \mathrm{n}=$ Number of samples.

Table II: Dimensional stability at various time intervals.

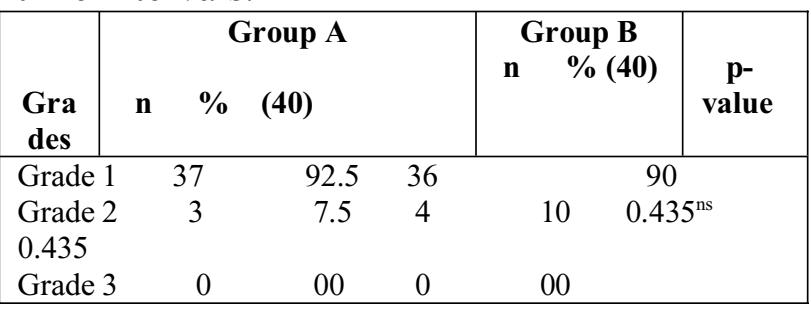

square $\left(\mathrm{X}^{2}\right)$ test.

* P-value obtained from Chi

$* \%$ : Percentage of samples.

$* \mathrm{n}=$ Number of samples, ${ }^{*} \mathrm{~ns}=$ Not

Significant.
Table III: Surface detail at10 minutes.

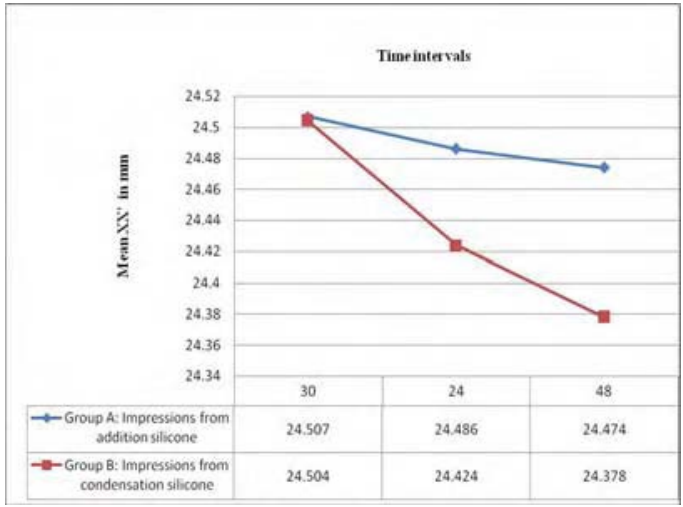

Fig 4: Showing mean measurement on impression of standard S.S die at various time intervals.

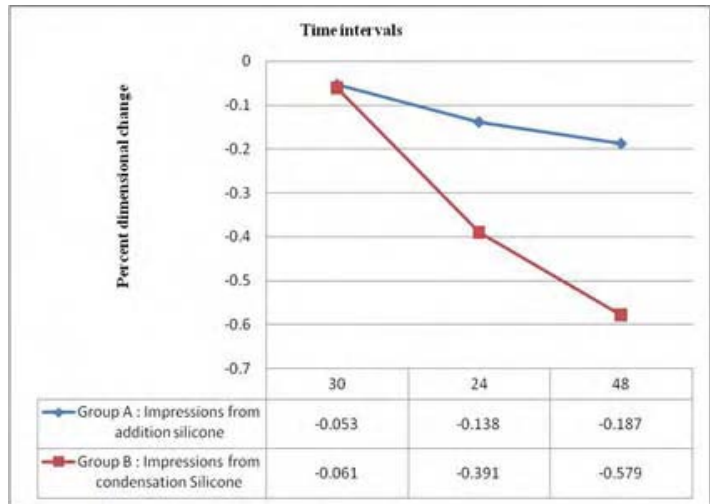

Fig 5: Showing percent dimensional change of impression at various time intervals.

As in this study, Eames et $\mathrm{l}^{11}$ found accuracy and dimensional stability of elastomeric impression materials (addition silicone, condensation silicone, polysulfides and polyether's) at 30 minutes of impression making possess no significant difference ( $\mathrm{p}>0.05)$.

Addition silicone impressions at 24 hours of impression making had dimension stability significantly higher $(p<0.05)$ than that of condensation silicone. The percent of dimension change (Fig-2c) of condensation silicone $(-0.391 \%)$ was more than that of addition silicone $(-0.138 \%)$ in our study; The 
obtained result in our study corroborates with the recommendation of ADA specification Number 19 for elastomeric impression materials i.e. maximum percentage of dimensional change is to be $0.50 \%$ after a minimum of 24 hours $^{8,11,12,13}$.

In our study, addition silicone at 48 hours of impression making had dimension stability significantly higher $(p<0.05)$ than that of condensation silicone. The percent of dimension changes of condensation silicone $(-0.580 \%)$ was more than that of addition silicone $(-0.187 \%)$, Similar results were found in a study $9,14,15$ that vinyl polysiloxane (addition silicone) was significantly stable than that of condensation silicone at 48 hours of impression making. This dramatic shrinkage/percent of dimension change in condensation silicone may be due to polymerization byproduct alcohol volatilization in the set material ${ }^{13,14}$ thereby producing poor result.

The statistical analysis of the data obtained from the Impressions of standard stainless steel die according to surface detail reproduction at 10 minutes of impression making revealed that there was no significant difference in surface detail reproduction between Group-A and Group-B; $(\mathrm{p}=0.435)$, similar to the study conducted by Ciesco et $\mathrm{a}{ }^{15}$. Grundke et $\mathrm{al}^{16}$ found that there were no differences in the surface tension between addition and condensation silicone impression materials as it is the key role in surface detail reproduction. Viscosity plays an important role in surface detail reproduction ${ }^{17,18,19}$; increase in viscosity decreased in the surface detail reproduction capacity ${ }^{3,20}$ and in this study we have used putty variety impression materials (very high viscosity).

\section{Conclusion}

From this study it is concluded that at 30 minutes of impression making addition silicone (vinyl polysiloxane) and condensation silicone (hydroxyl terminated polydimethyl siloxane) impression materials produced similar dimensional stability but at 24 hours and at 48 hours of impression making addition silicone appear to maintain its dimensional stability more than that of condensation silicone impression materials. It is also concluded that surface detail reproduction of addition silicone and condensation silicone impression materials are similar at 10 minutes of impression making.

\section{Reference}

1. Petrie CS, Walker MP, O'Mahony AM, Spencer $\mathbf{P}$. Dimensional accuracy and surface detail reproduction of two hydrophilic vinyl polysiloxane impression materials tested under dry, moist, and wet conditions. J Prosthet Dent, 2003, 90(4):365-372.

2. Rosenstiel SF, Land MF, Fujimoto J (ed.). Tissue Management and Impression Making. In Contemporary fixed prosthodontics, $4^{\text {th }}$ ed, Elsevier, Mosby, 2007, pp. 444-462.

3. Hamalian TA, Nasr E , Chidiac JJ. Impression materials in fixed prosthodontics: influence of choice on clinical procedure. J Prosthodont, 2011, vol. 20, pp. 153-160.

4. Hung SH, Purk JH, Tira DE, Eick JD. Accuracy of one-step versus two-step putty wash addition silicone impression technique. J Prosthet Dent, 1992 , vol. 67 , no. 5 , pp. $583-589$.

5. Baldissara P, Ciocca L, Caldari M, Scotti R. Comparative analysis of some condensation silicon impression materials. Dent News, 2005, vol. XII, no. III, pp. 34-38.

6. Mandikos MN. Polyvinyl siloxane impression materials: An update on clinical use. Aust Dent J, 1998, vol. 43, no. 6, pp. 428-34.

7. Rubel BS. Impression materials: A comparative review of impression materials most commonly used in restorative dentistry. Dent Clinc North Am, 2007, vol. 51, no. 3, pp. 629-642.

8. Walker MP, Rondeau M, Petrie C, Tasca A, Williams $\mathbf{K}$, Surface quality and long-term dimensional stability of current elastomeric impression materials after disinfection. $\mathrm{J}$ Prosthodont, 2007, vol. 16, no. 5, pp. 343-351. 
9. Clancy JMS, Scandrett FR, Ettinger RL. Longterm dimensional stability of three current elastomers. J Oral Rehab, 1983, vol. 10, pp. 325333.

10. Ahmad S, Tredwin CJ, Nesbit M, Moles DR. Effect of immersion disinfection with Perform-ID on alginate, an alginate alternative, an additioncured silicone and resultant type III gypsum casts. Br Dent J, 2007, vol. 202, pp. E1-7.

11. Eames WB, Wallace SW, Suway NB, Roger LB. Accuracy and dimensional stability of elastomeric impressionmaterials. J Prosthet Dent, 1979, vol. 42, no. 2, pp. 159-162.

12. Anusavice KJ (ed.). Impression Materials. Phillips' science of dental materials. $11^{\text {th }}$ edition, Philadelphia, Saunders, 2008, pp.213, 214,215,221 \& 224.

13. Shetty P, Rodrigues S. Accuracy of elastomeric impression materials on repeated pours. J Indian Prosthodont Dent, 2006, vol, 6, no. 2, 68-71.

14. Franco EB, Cunha LF, Benetti AR. Effect of storage period on the accuracy of elastomeric impressions. J Appl Oral Sci, 2007, vol. 15, no. 3, pp. 195-8.

15. Ciesco JN, Malone WFP, Sandrik JL, Mazur B. Comparison of elastomeric impression materials used on fixed Prosthodontics. J Prosthet Dent, 1981, vol. 45, no.1, pp. 89-94.
16. Grundke K, Michel S, Knispel G, Grundler A. Wettability of silicone and polyether impression materials: Characterization by surface tension and contact angle measurements. Elsevier, 2008, vol. 317, no. 1-3, pp. 598-609.

17. Finger WJ, Kurokawa R, Takahashi H, Komatsu M, Sulcus reproduction with elastomeric impression materials: A new in vitro testing method. Dental Materials, 2010, vol. 24, no. 12, pp. 1655-1660.

18. Wadhwani CPK, Johnson GH, Lepe X, Raigrodski AJ. Accuracy of newly formulated fast-setting elastomeric impression materials. J Prosthet Dent, 2005, vol. 93, no. 6, pp. 530-9.

19. Powers JM, Wataha JC (ed.). Impression Materials. Dental materials properties and manipulation. $9^{\text {th }}$ edition, Mosby, Elsevier, 2008, pp. 194.

20. Rodriguez JM, Bartlett DW, The dimensional stability of impression materials and its effect on in vitro tooth wear studies. Dental Materials, 2011, vol. 27, pp. 253-258.

Address of Correspondence: Dr. Riwa Karki, Shree Birendra Hospital, Chhauni, Kathmandu, Nepal E-mail: riwazkarki@yahoo.com 